\title{
The Promises of Education Policy in Bangladesh to Reform Examination and Evaluation: Reality or
} Myth?

\author{
Dr. Sumera Ahsan
}

\begin{abstract}
Bangladesh has made progress in net enrollment and gender equity in education sector. However, the national assessment results show that the learning achievement of the students is at stake, which is a concern. Ironically, the public examination results show much better picture of students' learning than the National Assessment. This difference in results questions the country's examination and assessment system- can it really assess students' learning or it is assessing students' rote memorization? In this situation, the promises of National Education Policy of Bangladesh 2010 to reform examination and evaluation of student assessment gives us hope for a new, modern, fair, and uniform assessment system which will replace the old rote memorization based system. Using the Critical discourse Analysis and Discursive Psychology, I tried to answer- how does the National Education Policy re-invent the meaning of examination and evaluation through the discourse?, how does the policy as a text produce or reproduce the power relations of the society?, and how do different actors of education create meanings from this policy document? First, the exclusion of prominent theories and research on assessment and more focus on political manifesto makes the policy more political and educational. Second, the vague idea of creative question works as hegemony to replace the existing evaluation system focuses more on summative assessment than formative. The language, syntax, and use of words portrayed the evaluation and examination as a top down model of implementation rather than bottom-up or participatory, a management system where equality is seen as fair rather than equity, a set of activities where teachers and supervisors are given responsibilities with no real power to challenge the status quo, and ultimately a society that conforms the existing unequal and discriminatory power relations of the society rather than challenging it or changing it. Thus, the promises of education policy to reform the examination and evaluation create a myth, not a truth.
\end{abstract}

Keywords: Assessment, Evaluation, Examination, Reform, Discourse Analysis, Education Policy

\section{Introduction}

Bangladesh has made impressive progress in educational outcomes since independence in the 1970s. A rapid increase of enrollment and the improvement of gender equity have been major achievements. However, improving the quality of education remains a challenge. A nationwide sample survey of primary school students completing class five, carried out by Campaign for Popular Education (2000), showed that only 1.6 percent of the children acquired all of the 27 basic competencies tested in the survey. Half of the children failed to achieve 60 percent or more of the basic competencies. This finding is consistent with earlier results found from Education Watch report. Education Watch 1999 reported that only one-third of the children aged 11-12 years performed at a qualifying level in the test of basic competencies. For readers in grades 1,2 , and 3, the average oral reading fluency (ORF) rates were 16, 23, and 28 correct words per minute (CWPM), respectively. For 2nd grade readers, 1 in 4 (24 percent) and for 3rd grade readers, 2 in 5 students (43 percent) could not answer a single reading comprehension question [United States Agency for International Development (USAID, 2018)]. Nath, Mohsin and Chowdhury (1997) tested a large sample of 11-and 12year- old rural children asking them a total of 13 mathematics questions. Only 28.7 percent of the children could answer all the question items correctly.

Interestingly, the result of public examinations shows much better picture than this (Japan Bank for International Cooperation, 2002). This inconsistency between the two pictures of student achievement raised crucial questions about examination and assessment system of Bangladeshhow much valid and reliable is our evaluation and examination system?; does it or can it assess actual learning of the students or only the rote learning?; is the assessment in the school and classroom promoting students' learning or the rote learning? The questions are vital as enhancing students' learning with feedback and guidance is the most important role of students' assessment (Hattie, 2009; Bloom, Madaus \& Hasting 1981; Black \& William, 1998; Popham, 2011; Guskey, 2003).Under this circumstance, the promises of national education policy of Bangladesh Government to reform the examination and evaluation system, looks lucrative. In this paper I tried to reveal the particular way of talking about and understanding of the world related to examination and evaluation by analyzing this policy document using discourse analysis.

\section{Research Question}

By analyzing the chapter "Examination and Evaluation" of the National Education Policy of Bangladesh as a text, I have tried to investigate:

1) How does the National Education Policy re-invent the meaning of examination and evaluation through the discourse?

2) How does the policy as a text produce or reproduce the power relations of the society?

3) How do different actors of education create meanings from this policy document?

\section{Methodology}

The texts: To understand how the social world is created within and by this policy document, I have analyzed two different texts. I have analyzed the chapter titled "Examination and Evaluation", a part of the "National Education Policy, 2010" of Bangladesh to see how a specific world is created and produced by this policy paper. For this, 


\section{International Journal of Science and Research (IJSR) \\ ISSN: 2319-7064}

ResearchGate Impact Factor (2018): 0.28 | SJIF (2018): 7.426

I have employed Critical Discourse Analysis (CDA) as a framework and method for analysis. Along with the policy paper, I have also analyzed a text, which is a transcribed version of a group discussion among several stakeholders of education. The aim of this analysis was to understand how different actors who are related in implementing the policy have constructed their own discourse from this policy document. For analyzing the group discussion, Discursive Psychology was used.

Critical Discourse analysis: I used Critical Discourse Analysis (CDA) to interpret the discursive aspect of knowledge production of the policy document for several reasons. First, $\mathrm{CDA}$ is much suitable to analyze policy document as the policies are, by definition, texts imbued with authority (Rogers, 2004).According to Ball (1990), policies are particularly important expressions of social power as they convey the values of authoritative actors and institutions whose particular forms of knowledge about the social world are reflected in these texts. Secondly, this approach is much suitable for my aim of exploring the representation of power relation in the society. The "critical" aspect of critical discourse analysis demands that the linguistically oriented dimensions of a study be directed at a critique of existent social and political relations of power with the explicit goal of disrupting them (Gee, 2004). When we examine the forms of knowledge authorized through policy, and excluded by it, we can discern social relations of power that govern policy production, circulation, and implementation. Thirdly, I used CDA as itcan provide both framework or theories and methods for studying the relation between discourse and social development (Jorgensen and Phillips, 2002). CDA is constructivist in methodology, which believes that knowledge is socially constructed and shaped by relations of power that are both material and discursive. It rejects the assumptions of structuralism and, instead, asserts that certain discourses are privileged by their relationship with dominant groups in society and are, themselves, constitutive of social relations (Rogers 2004). Therefore, critical discourse analysis is a suitable method in analyzing policy document to reveal how the discourse has been created and how does it represent the power dynamics of the society. I have employed Fairclough's threedimensional model of CDA to analyze the text. The three dimensions are: (1) Linguistic features of text, (2) discursive practice and (3) social practice. For this study I have focused on these three dimensions. I have focused on the linguistic features such as vocabulary, grammar, syntax and sentence coherence to understand the particular usage of language. I have also looked into the processes relating to the production and consumption of the text to reveal the discursive practice of the discourse. Lastly, I have explored the wider social practice to which the communicative event belongs and creates.

I have also drawn from Laclau and Moufee's (1985) Discourse Analysis to focus on the idea of reality vs. myth. With this approach I explained the concept of nodal points, master signifiers, chain of equivalence, identity, antagonism and hegemonic interventions to sketch the world-view produced by the policy document.

Discursive Psychology: To reveal the discursive construction of the policy document by the different actors of the examination and evaluation, I have analyzed a text produced from the group discussion on this chapter of the policy document by several stakeholders using discursive psychology. The aim of discursive psychology, unlike the critical discourse analysis is to explore the ways in which people's selves, thoughts and emotions are formed and transformed through social interaction and to cast light on the role of these processes in social and cultural reproduction and change (Jorgensen \& Phillips, 2002).

\section{Analysis and Findings}

The analysis of the texts is presented here in different themes that emerged from the texts. The themes are interrelated and answer the first two research questions in an integrated manner. In the first part I'll describe those themes. The themes explain the nature of discursive knowledge produced by the policy document. The different perspectives of creating reality from the different stakeholders of education or evaluation sector are presented in the second part, which answers the last research question.

\section{Part-I: The discursive knowledge produced by the policy document}

\section{Whose Policy and for whom?}

The Education Policy, 2010 has been formulated by the Ministry of Education, Government of the People's Republic of Bangladesh. The policy document has total 28 chapters including the chapter "Examination and Evaluation. There must be several strong voices in this chapter who introduced and contributed to build different ideas of this chapter. This document made that voice invisible and there is no trace of that voice. Only the names of the committee members who developed this document are listed in the annex, with almost no mention of the policy production process. The final product has been presented as a policy text with less focus on who produced it and how, but as a list of activities need to be accomplished.

The text has versions available both in English and Bangla. Unlike the previously produced national policy, this National Education Policy was circulated online to solicit feedback from different stakeholders. There were discussions arranged with different stakeholders to talk about the policy which was a good initiative. It seems that the government was trying to be democratic and transparent in producing this text. However, only few people in Bangladesh has the capacity, resource, and skill to have access to this document as the internet facility is not available or affordable for all people of the country the same way, especially in the rural area. Few people had the real power to critique this document. Therefore, the text got the access to a specific elite and privileged group for their critique.

\section{Education policy: how political or educational as a document?}

Intersexuality occurs when different discourses and genres are articulated together in a communicative event (Jorgensen $\&$ Phillips, 2002). In this piece of text, the election manifesto of the Government as a political party is reflected

\section{Volume 8 Issue 8, August 2019}




\section{International Journal of Science and Research (IJSR) \\ ISSN: 2319-7064}

ResearchGate Impact Factor (2018): 0.28 | SJIF (2018): 7.426

presenting the political characteristics of the document. The prime minister states in the preface, “...this Education Policy is the product of the preparation that Awami League (as a political party) had for public service." (Ministry of Education, 2010, p. iv), and also, "In our Election Manifesto 2008, we set the goal of building up Bangladesh as a poverty-free, non-communal, liberal and democratic state. Without the right kind of directives and guidance, no right programs can be undertaken." (National Education Policy, 2010, p. iii).

When the text indicates three areas of learning to evaluate, only then bloom's domain of evaluation is mentioned. Besides, it does not present any of the theories of education and/or evaluation. There are many theories, global and local research and findings on student examination and evaluation. No global or local research on educational assessment or no theory of educational assessment was mentioned. Therefore, the document seems much more political than educational.

\section{The promises}

\section{i)Traditional vs. creative method of evaluation: a hegemonic intervention?}

The mostly appeared words in the selected text are examination and evaluation. The word assessment is not used and in every case the word "evaluation" is used which is more summative, product focused, high stake examination based, end oriented compared to the word assessment which is more formative, process oriented, classroom based and focused on mean (Broadfoot, 1996). Even only one time when they meant classroom assessment they used the word "continual evaluation". The text intentionally left words that focus assessment and replaced it with the word evaluation to focus more on standardized test. The proposed examination and evaluation system is presented as a panacea to "fix up" the already existing examination and evaluation system. To describe the already existing examination system they used the word "traditional" and "not much effective" in front of the word examination and proposed an alternative, which is much "modern"(p.51). However, to propose an alternative to this "traditional" way of evaluation, while articulating the strategies for the proposed fair, creative and effective evaluation system they only promised to have "proper attention", "proper initiatives", "effective steps", "setting proper rules", "play an important role" in almost all the cases which does not give any specific idea on the ways to create this proposed evaluation system.

Using Creative Questions (CQ) to increase students' creativity is a special feature of this new curriculum. The name is misleading as in the world literature this is termed structured questions. In structured questions, students are given a situation or prompt. Then, they need to answer a set of questions which assess their knowledge, understanding, application and higher order learning such as analyzing, synthesizing, evaluating, and creating. How these types of questions will help nurture students' creativity and not invoke rote memorization is not explained. The introduction of 'creative method of evaluation' to remove the pre existing rote learning based evaluation can be seen as a hegemonic intervention which promises to solve the crucial problem of memorization based examination.

This policy wants to bring change in student assessment by changing the public and summative assessment. It is very clear that CA or formative assessment is not seen as a as a solution for this problem of rote-learning. The three aims and objectives and the three strategies mentioned for this section are very general and can be related to any kind of assessment. However, in one statement, the policy suggests that there should be continuous assessment in all grades, which indicates the importance of CA. How CA should be conducted or what is the present status of CA in schools are not mentioned. All the guidelines, rules, regulations, and training for the teachers are focused on training the teachers as question setters, examiners, and textbook writers and do not prepare them for regular classroom assessment. In this way the policy created teachers' identities as examiners and test developers rather than classroom teachers who focus on $\mathrm{CA}$ in a formative way.

\section{ii) Evaluation: Afair system of management?}

Most of the time the word evaluation is accompanied by adjectives such as proper, right kind of, effective, fair, appropriate, creative to propose a utopian examination and evaluation system to the reader. To provide the image or purpose of examination and evaluation the words "regulatory system", "effective system", "strategy", "checking" are used. It seems that the examination and evaluation system is a mechanical process with no or minimum involvement of human being, making it objective and unbiased. It explains the evaluation system from a management perspective (for example, managing, strategies, system, efficiency, regulatory system- these words are used) but excludes human right-based approach (for example, words like right, equity, child, potential these are absent). Only in few cases the text talks about teachers and students. Do they want to make it value free to present it as a fair and ethical evaluation system? When they talked about the standard and quality, they used the words "identical questions", "uniform question papers", "uniform evaluation system", and "uniform grading system". They want to echo for an ethical, fair evaluation system based on equality, leaving behind "equity". The text was a political document like any other policy document. Shore and Wright (1997) believe that policies are political in nature but are disguised by objective, neutral, legal-rational idioms.

\section{iii) The model of Implementation: Top down or bottom up?}

The language of the text suggests a top down model of planning and implementing projects, not a bottom-up or participatory one. For example, the text delineates, "The proper implementation of this system will depend on the preparation of right kind of textbooks, set of rules to prepare question papers and an effective understanding of the process by the paper setter and students. So effective steps will be taken to prepare the right kind of textbooks, to set proper rules and to create appropriate awareness and knowledge of all concerned" (p.51). It depicts a very strict top down model where the plans and decisions will be taken by some "knowledgeable" people, and the people who implement it will be made aware and knowledgeable about the decisions. 


\section{International Journal of Science and Research (IJSR) \\ ISSN: 2319-7064}

ResearchGate Impact Factor (2018): 0.28 | SJIF (2018): 7.426

iv) Who takes the responsibility?

If we analyze the modality of the text, all the sentences are written in passive voice, which does not present any actor for the verb. For example: Proper attention will be paid...., initiatives can be taken....., effective steps will be taken...., ...will be conducted...., ...will be held..., ...will be discouraged..., ...will be awarded..., ...will be in practice.... to mention some. Who will pay attention, take steps, make something happen or practice, award or will allow is not mentioned. It is interesting that only in one case the word "should" is used and that was: "The teachers and the administrators of the institutions should take initiatives to prevent unfair means in the examination". It seems that they are more vocal and authoritative to announce teacher's responsibility but more implicit to announce Government's responsibility. And when talking about student the word "allowed" is used which was not used in other cases: "In case of failure in one or two subjects at the secondary level students will be allowed to take part in the examination of those subjects for two times (p.52)". This modality of language represents the existing power structure where responsibilities are imposed to teachers by Government and the power is polarized to the end of the Government.

\section{v) Identities: who are included and who are excluded?}

Identities of the examiner and the examinee are crucial to analyze. The identity of the examinee is made with the notion of 'knower', who has to give the proof of his/her knowledge and creativity to the examiner who is in the position of judge to evaluate and report the result. Their other identities (for example the identities as learner, human, child for the examinees and identities such as human, teacher, leader for the examiners) has been excluded. By eliminating other possible identities which makes the subject over determined (Jorgensen \& Phillips, 2002, p. 41) the two groups examiner and examinees are created.

The students have two types of representations-as learner and examinees. The learning is seen as something, which is measured by the examination, where the focus is on examination and evaluation not in learning. This means that, these two social identities are mutually excluding each other creating antagonism. The "hegemonic intervention" (Laclau \& Mouffe, 1985, p.136) put a dominant end to this collide by fixing a meaning. They define the student as examinee who needs to proof his/her academic achievements with the test score.

\section{vi) Changes or reproduces the existing societal power relation?}

"In our Election Manifesto 2008, we set the goal of building up Bangladesh as a poverty-free, non-communal, liberal and democratic state. Without the right kind of directives and guidance, no right programs can be undertaken." (Ministry of Education, 2010, p. iii).The education policy clearly presents a promise to build an education system that will help developing Bangladesh as a poverty-free, noncommunal, liberal and democratic state, which needs major changes including in educational institutions and social structures. However, in the education policy document, this promise remains elusive as we see the same representation of social structure and power dynamics in the text sections explained earlier and in next sections.
The chapter guides how to reward a student with good grades, such as giving scholarships but do not talk about how to help the students who cannot manage to have good grades. Now, who gets a good grade and what happens to them? The one who can afford to go to good schools (mainly private schools), can have help from their educated parents or can afford private tuition will get good grades and eventually will receive scholarships and get into the universities. In contrast, who get a lower grade? The one who cannot afford to go to a good school or cannot complete the higher secondary level of education or who is first generation school goers, or who have no support for private tuition, will get a low grade. Tracks are made for them too; they will move to technical and vocational education and eventually be in the factories, informal economies and other low paid jobs. It depicts that the underlying scenario is the same, based on the present unequal power structure.

When there are different headings for primary and secondary education, and higher education with descriptions on how to improve these sectors, there is only one line for the technical and vocational education and one line for madrasah education. Even though there are separate chapters on these two, but not focused on examination and evaluation part. The document shows much less importance in these two streams of education compared to the main stream though these streams are suffering from more issues and problems (Asian Development Bank, 2015). It seems that technical and vocational education and madrasah education has failed to attract the attention of the authors as it fails to attract the attention in the society and are neglected as a non-elite sector of education.

Though the authors try to identify and eradicate some issues and problems, they try to solve it but ignore the underlying deeper roots of the causes for that problem. For example, in the text it is written that, "guidebooks, note-books, private tuitions, coaching center etc. are hindrances to quality education system. Steps will be taken to 'stop' all these.' However, they do not hit the major cause of all these shadow education, which are lack of quality education in schools, teachers' low salary structure, lack of support for the first generation school goers, and the most important one, evaluation system that encourages rote learning. Though they talk about rote learning, wants to eliminate rote learning, but do not link it as a major cause of shadow education.

When we see the repeated mention of creative method, test, evaluation throughout the text, we become optimistic that may be the new evaluation system is trying to recreate the system in a new way so that the creativity of the children is evaluated and thus valued and nurtured. However the imposition of too much high stake tests (after grade, 5, 8, 10, and 12) and the way it promises to create standardized tests makes it elusive again as the educationists over the globe is criticizing standardized and high stake tests as a deterrent of students' learning (Jones, Jones, Hardin, Champman, Yarbrough, \& Davis, 1999; Mayer, 2002). Therefore, though the text gives us an illusive impression of a world we dream about, it actually proposes the models and solutions that create the same world we live in. 


\section{International Journal of Science and Research (IJSR) \\ ISSN: 2319-7064}

ResearchGate Impact Factor (2018): 0.28 | SJIF (2018): 7.426

It seems that they are talking about equal rights and try to develop a society, which is just and fair as they propose identical questions, uniform evaluation system and uniform grading system. However, a country where so much discrimination is seen based on rural-urban area, different districts, gender, ethnicity and even in different schools unified and identical evaluation and grading system can only reproduce the same amount of inequalities in the society.

It is assumed that the efficiency and dynamism of employees can be increased by transforming them from one board to another. "The officers and other employees of Education Boards will be transferred from one Board to another in order to increase their efficiency and dynamism"(p. 52).However, it takes time for any employees to situate themselves in the context; for any sustainable development of any sector continuous and step by step change of activities need to be accomplished. Therefore, the meaning of dynamism taken for this text is superficial, and satisfies the tradition of education management system of Bangladesh. However, it does not promote long-term development of a sector.

The whole world view of our society is represented in the text when they are repeatedly promising to reward the students having good grades and penalizing the teachers for neglecting their duties, they are silent regarding promising any support to give for the students and teachers who need so. And when it comes about raising teachers' honorarium for checking scripts they do not pronounce any strong assertion but say, "The honorarium for checking scripts will be positively reviewed" (p.53).

\section{Therefore.....Promise for a just and equitable society:} reality or myth?

Here the moments (Laclau \& Moufee, 1985) 'measurement', 'knowledge', 'rote learning', 'regulation', 'unified grading system', 'question papers', 'effective steps', 'creative system of evaluation', 'scholarship', 'continual evaluation', 'failure', 'penalized' have created a chain of equivalence for creating a discourse through their relational meanings to each-other. It identifies the conventional evaluation system as a tool to measure the rote learning and see it, the rote learning as a problematic and presents creative system of evaluation as a solution to the problem. It also suggests unified grading system and having same tests for the public examinations as a step towards a more just world. For implementing all the policies the text emphasizes on 'effective' and 'appropriate' steps, which leaves a place for being a floating signifiers, which can be defined in different ways. The system also emphasizes on rewarding the high achievers based on the public examination results and define the limits for taking examinations of a student who fails.

The Nvivo analysis shows that the most frequently used words are- examiner (34, weighted percentage 4.98), evaluation (30), system (22), education (12), students (12), class, i.e., grade (9, weighted percentage 3.96), levels (9), continual (9), proper (8), public (8), effective (7), graduation (7), and secondary (7). The tag cloud looks like this:

2010 acquisition aims allowed also another applicable assessed awarded aware basis besides board books

case caution centers certificate ClaSS coaching completion comprehension concerned

conducted continual creative curriculum dakhil date education effective

evaluation

\section{examiners}

s failure fixed formulate grading graduation guide held higher $\mathrm{hsc}$ important included

initiatives institutions internal junior kind knowledge known learning levels made means

method national necessary note objectives one paper part personality policy post practice prepare

primary private proper public qualities question regulation results right rote rules

scholarships school scripts secondary set special steps strategies Students

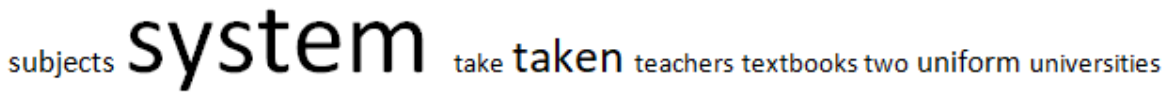

Figure: Tag cloud for the chapter "evaluation and examination" of National Education Policy, 2010 of Bangladesh

Volume 8 Issue 8, August 2019

www.ijsr.net

Licensed Under Creative Commons Attribution CC BY 


\section{International Journal of Science and Research (IJSR) \\ ISSN: 2319-7064}

ResearchGate Impact Factor (2018): 0.28 | SJIF (2018): 7.426

If we analyze how in the text different agencies were mentioned, we see that the examiner and/or examination is much more important than the students and/or learning (5). The evaluation and examination is depicted as a management system with related word for example, levels, secondary, public, step, effective class. It is also interesting to notice that the words certificate, completion, prepare, grade, graduation have come more frequently than the words learning, or creativity, which helps us to see the aim of evaluation endeavor. Also, the first set of words actually encourages shadow education or private tuition, which they however are extremely adamant of banning in their suggestions afterwards, which is contradictory. Therefore, though the text creates a myth of equity and quality, they ultimately conforming to the existing world with injustice, inequality, and highly structured in power relation.

The unified grading system and the question papers (test) is presented as an effective way which will enable to compare among different student's academic achievements based on their unified grades, to be more just to the students which is actually a "myth". This myth of justice tends to establish its role as a "totality" (Jorgensen \& Phillips, 2002, p. 39). The school system which prepares the students for the examination is not uniform in quality. Nationally, students from poor households perform lower than students of wealthy households. Children from poor families lag at least three-fourths of a school year behind their richer peers in the subject Bangla (language), and half a school year behind in mathematics (World Bank, 2013). There are discrepancies in the academic performances among schools, too. Based on data from the SEQAEP impact evaluation baseline survey (2008), the World Bank (2013) reports that performance of the students of government secondary schools and private schools that do not receive subventions from the government is better than that of the vast majority of the non-government schools getting subventions. Studies show that performance disparities among schools are larger than among students within a school (World Bank, 2013). Therefore, when the society is based on an inequality and where the students are having different quality of schooling, does the unified grading or the use of same question papers (test) can ensure a just and equitable system? Therefore, though it describes the unified grading system and evaluating the students based on the same test as objective methods and a symbol of justice, it is not a reality but a myth.

Part-II: Discursive interpretation of the policy discourse by the stakeholders

This analysis is performed on a text, which is a transcribed version of a group discussion among several stakeholders of education. The aim of this analysis was to understand how different actors who are related in implementing the policy have constructed their own discourse from this policy document. For analyzing the group discussion, Discursive Psychology was used. However, this discussion was short and may not include all the nodal points to give it more complete understanding of their own constructed discourse. However, it obviously gives us an idea of how different actors (school teachers, head teachers and educationists) at some point thinking, talking, and understanding the document.

\section{Who belongs to where?}

The discussion text shows that Teachers mostly commented on the issues of private tuition, creative method of evaluation and textbooks, which belongs to a comparatively micro system and mostly related to their own work and responsibility. Head teachers were more concern about the public examinations, scholarship to the students and creative method of evaluation, which can be considered as the components of a meso system related to school and community. The Educationists gave their opinions mainly about public examination, standardization of test and unified grading system, which can be categorized to a more macro system related to policy, institution and society. It is interesting to notice that they confirm their own identity to belong in a specific group of people with specific world to consider.

\section{Whose school and for what purpose?}

It was interesting to notice how the different stakeholders see their attachment with schools, which is depicted with the choice of their language in the discussion group. One teacher said,

"We try our best to teach the students effectively.

We also try to effectively evaluate their

performance. However the evaluation system

changes after each several years with the change

of government which makes it tough for us to

catch up every time and even sometimes without having training."

Here the teacher used the word "we" to represent the teachers as a group. The group identity seemed stronger than their self-identity while criticizing the abrupt change in evaluation system. In another occasion another teacher said,

\footnotetext{
"Our school is one of the least performing schools in terms of public examination results. However, the baseline result of the students while entering should also be taken into account and compare with the final result to see the progress. It is not fair to give award to " $x$ " schools because of their brilliant result. It is not much of their credit but the credits of the students as they selected the most academically brilliant students for their

school. But we teach the least performing students and try to make best out of them. Why should not we get any reward?"
}

When the teacher talked about school she was recognizing it as our school. Her voice reflects her awareness of the unfair criteria of evaluation for schools and the competition based on extrinsic rewards. However to present the head teacher's voice-

"My school is in a very rural area. Poverty is a very big issue here. Students, come to school unfed and cannot concentrate on their learning. The school feeding program of the government can enhance the learning opportunity of these students here. ..... Also my teachers need training

to implement the newly proposed creative evaluation system as most of them do not have 


\section{International Journal of Science and Research (IJSR) \\ ISSN: 2319-7064}

ResearchGate Impact Factor (2018): 0.28 | SJIF (2018): 7.426

much good idea even about evaluation in the classroom."

It is interesting to notice that when the head teacher is talking about school he is saying "My school" which shows much clear possession towards the school. He is also concern about getting the benefits from government as may be he identifies himself as an agent to have change in the school. His idea about the teachers reveals his less reliance on their quality of instruction.

\section{Shadow education remains in shadow}

There were different opinions from different stakeholders regarding private tuition, coaching as a form of shadow education. The educationists were very much vocal and adamant about banning the shadow education as we can see one of them said,

"It [private tuition] does not only ruin the creativity of the students but also encourages the teachers to neglect their classes in the school. This policy has a good intention to ban these private tuition and coaching which is really harmful for the children".

The head teacher argues:

"I know that it is harmful for the students....Most of the students are first generation school goers in my school who usually cannot manage any help from their family. The examination system is set in such a way that they need extra preparation for passing the tests".

The teacher said:

"Before banning private tuition the salary of the teachers should be increased. With this poor structure of salary a teacher has no other option but to do private tutoring unless he or she has other job or business."

The different stakeholders are creating, shaping and viewing this discourse from different perspective. The educationist has a utopian view with less concern about the practical aspects of it. On the other side though the head teacher recognized the risk of private tuition for the students he is also aware of the very real context of this issue to occur. The teacher is directly related to this activity and his world view is directly challenged by the proposal which made him/her act directly and demand his/her equal right and justice.

\section{High stake exams: check points or drop out points?}

The new policy document proposed a new high stake public examination at the end of grade eight called Junior Secondary Certificate Exam. However the Educationists and the head teachers have their different construction of the world. According to the head teacher,

"In the schools we have less ability to check the accountability with our low resources. For example in my school it is not possible to check the progress of each student and the effectiveness of each teacher and even the activities of each supervisor all by myself. So if there is a public examination, it will create responsibility and awareness in teachers, students, supervisors and even in parents which is helpful."
However the educationist argues,

"With the increase in number of high stake tests there can be increase in the drop out ratio especially for the poor, marginalized, and girl students. Many of the developing countries are quitting their previously established high stake tests now. And it is ridiculous to introduce new high stake tests now in our country".

Here, we see that the head teacher thinks that the students, teachers and supervisors need to be checked in order to make them responsible in their duties. While the head teacher sees the public exam as a check point, the educationist sees it as a hindrance which can create more inequalities in education.

\section{Discussion and Conclusion}

The text gives us an impression of having determined to "fix up" the "traditional" evaluation and examination system, which is ineffective and unfair. For that it juxtaposes an elusive "modern" evaluation system (creative method of evaluation), which is fair and effective. However, the discourse analysis reveals the underlying assumptions and intention of the discourse created by this text actually represents the existing unequal power relationship of the society, presenting the utopian modern evaluation system as a myth.

The education policy is one of the ways to fulfill the Election Manifesto 2008 of the existing political party, which sets the goal of building up Bangladesh as a povertyfree, non-communal, liberal and democratic state. It criticizes the previous evaluation system as being ineffective and proposes an alternative evaluation system which, measures students' creativity instead of rote memorization. It also discusses to make the whole evaluation system more unified and similar in different streams (general, madrasah and technical and vocational education). But it does not see the underlying deeper problem, which needs to be solved. If we still have the very different content, philosophy and teaching learning quality in the different streams, how much can it bring these streams to a basic platform just by having similar evaluation system is under question. Similarly when the policy decides to take steps to stop guidebooks and coaching centers, does it intentionally exclude the root causes of these (for example first generation school goers, lack of quality teaching learning in the classroom, teachers financial need etc.)?

The policy has left the other meanings of the moments they have created, the field of discursivity (Jorgensen \& Phillips, 2002 , p. 41), which can offer an alternative articulation. In the alternative policy paper we could emphasize more on assessment in a formative way of improving the learning of the students (learners), rather than just to have an accurate and comparable measurement using a unified grading. Emphasis could be given to have strategies to improve the low academic achiever's learning achievement, (which is not easy and the effect is not always tangible) not just rewarding the high achievers with scholarships (which is easy to do and the effort is more tangible). When it talks about the eradication of guidebooks, coaching centers, it can also first 


\section{International Journal of Science and Research (IJSR) \\ ISSN: 2319-7064}

ResearchGate Impact Factor (2018): 0.28 | SJIF (2018): 7.426

look into the causes and try to remove the causes first which are lack of quality and social inequality which are again hard to remove. Therefore, technically the policy paper tries to put effort on the superficial problems with visible efforts such as "tests", "uniform grading system", "scholarships", "new creative questions". Though the government demands that this Education policy is aimed in building up Bangladesh as a "poverty-free, non-communal, liberal and democratic state", which was in their election manifesto, however through this policy the myth of "poverty-free, noncommunal, liberal and democratic state" has been established which is neither reality nor a totality.

\section{References}

[1] Asian Development Bank (2015). Innovative Strategies in Technical and Vocational Education and Training for Accelerated Human Resource Development in South Asia Bangladesh. Manila: ADB.

[2] Ball, S. J. (1990). Politics and Policy Making in Education: Explorations in Policy Sociology. London: Routledge.

[3] Black, P., \& Wiliam, D. (1998).Assessment and classroom learning. Assessment in Education, 5(1), 7174.doi: 10.1080/0969595980050102

[4] Bloom, B.S., Madaus, G.F., \& Hasting, J.T. (1981).Evaluation to improve learning. New York, NY: McGraw-Hill. doi: 10.1177/019263658206645327

[5] Broadfoot, P. (1996).Education, Assessment and Society: A Sociological Analysis: Assessing Assessment. UK: Open University Press.

[6] Campaign for Popular Education (2000).Education Watch: A Question of Quality: State of Primary Education in Bangladesh. Dhaka: CAMPE.

[7] Edwards, D. \& Potter, J. (1992). Discursive Psychology. London: Sage.

[8] Gee, J. P. (2004). Discourse Analysis: What Makes It Critical?: In An Introduction to Critical Discourse Analysis in Education, ed. Rebecca, R. M., NJ: Erlbaum.

[9] Guskey, T. R. (2003). How classroom assessments improve learning. Educational Leadership. 60 (5), 6-11.

[10] Hattie, J. (2009). Visible learning: A synthesis of over 800 meta-analyses relating to achievement. New York, NY: Routledge. doi: 10.1007/s11159-011-9198-8

[11]Japan Bank for International Cooperation (2002).Bangladesh Education Sector Overview. Tokyo: JBIC.

[12] Jones, M. G., Jones, B., Hardin, B., Champman, L., Yarbrough, T., \& Davis, M. (1999).The Impact of HighStakes Testing on Teachers and Students in North Carolina. The Phi Delta Kappan. 81 (3).199-203.

[13] Jorgensen, M. \& Phillips, L. (2002).Discourse Analysis: As Theory and Method. London: SAGE Publications.

[14] Laclau, E. \& Mouffe, C. (1985). Hegemony and Socialist Strategy: Towards a Radical Democratic Politics. London: Verso.

[15] Mayer, R.E. (2002). Rote versus Meaningful Learning. Theory into Practice, 41 (4), 227-232.

[16] Ministry of Education, Government of the People's Republic of Bangladesh (2010).

[17] National Education Policy. (2010). Dhaka: MoE.
[18] Nath, S., R., Mohsin, M., \& Chowdhury, A. M. R. (1997). Gender difference in the arithmetic knowledge of children in Bangladesh. Research in Education. 58, 35-45. doi: 10.1177/003452379705800104

[19] Popham, W.J. (2011). Assessment literacy overlooked: A teacher educator's confession. The Teacher Educator, 46, 265-273. doi: 10.1080/08878730.2011.605048.

[20]Rogers, R. (2004). An Introduction to Critical Discourse Analysis in Education. Mahwah, NJ: Erlbaum.

[21]USAID. (2018). Early grade reading barometer: Actionable data for a more literate world. Retrieved from

http://www.earlygradereadingbarometer.org/bangladesh /snapshots 